\title{
Evaluation of flexibility in FMS using SAW and WPM
}

\author{
Vineet Jain $^{\mathrm{a}^{*}}$ and Tilak Raj ${ }^{\mathrm{b}}$
}

${ }^{a}$ Department of Mechanical Engineering, Deep Institute of Engineering and Technology, Sohna, Gurgaon, India

${ }^{b}$ Department of Mechanical Engineering, YMCA University of Science and Technology, Faridabad, India

\section{H R O N I C L E A B S T R A C T}

Article history:

Received October 2, 2012

Accepted December 3, 2013

Available online

June 32013

Keywords:

Flexibility

FMS

$M A D M$

$S A W$

$W P M$

Fuzzy

\begin{abstract}
The evaluation of the most appropriate flexibility in the manufacturing sector is one of the strategic issues that may affect the Flexibile Manufacturing System (FMS). In this paper, a Multiple Attribute Decision Making Method (MADM) methodology is structured to resolve this problem. The two decision making methods, which are Simple Additive Weighting (SAW) and Weighted Product Method (WPM), are integrated with Analytical hierarchy process (AHP) in order to get the best use of information available. The aim of using AHP is to give the weights of the attributes and these weights are used in SAW \& WPM method for ranking of flexibility in FMS. Furthermore, the method uses fuzzy logic to change the qualitative attributes into the quantitative attributes. 15 factors are taken to evaluation of 15 flexibility. In this report, we concluded that Product Flexibility has the most impact in 15 flexibilities and Programme Flexibility has the least impact in these 15 flexibilities by this methodology.
\end{abstract}

(C) 2013 Growing Science Ltd. All rights reserved.

\section{Introduction}

A flexible manufacturing system (FMS) is designed to combine the efficiency of a massproduction line and the flexibility of a job shop to produce a variety of work pieces on a group of machines (Chan et al., 1997). The reason the FMS is called 'flexible' is that it is capable of processing a variety of different part styles simultaneously at the various workstations, and the mix of part styles and quantities of production can be adjusted in response to changing demand patterns. The evolution of flexible manufacturing systems offers great potential for increasing flexibility and changing the basis of competition by ensuring both cost-effective and customized manufacturing at the same time (Rao, 2007). Stockton and Bateman (1995) have suggested flexibility is the ability of a manufacturing system to:

- $\quad$ Change between existing part types

- $\quad$ Change the operation routes of components

- Change the operations required to process a component

* Corresponding author. Tel: +918901510570

E-mail addresses: vjdj2004@gmail.com (V. Jain)

(C) 2013 Growing Science Ltd. All rights reserved. doi: $10.5267 /$ j.dsl.2013.06.003 
- $\quad$ Change production volumes, i.e. either expansion or contraction

- $\quad$ Add new part types

- $\quad$ Add new processes to the system.

Several researchers have classified flexibility under different categories. Buzacott (1982) has classified it in two categories, i.e., job flexibility and machine flexibility. Park and Son (1988); Son and Park (1990) have identified four types of flexibility - process, product, demand and equipment flexibility. Browne et al. (1984) has proposed eight types of flexibilities. Azzone and Bertele (1989) have suggested six types of flexibility: process, product, production, routing, expansion, and volume flexibility. Sethi and Sethi (1990) have identified eleven types of flexibility: product, process, program, production, volume, routing, expansion, operation, machine, material handling and market flexibility. In this paper, fifteen flexibilities in FMS have been identified through literature.

1. Machine flexibility

2. Routing flexibility

3. Process flexibility

4. Product flexibility

5. Volume flexibility

6. Material handling flexibility

7. Operation flexibility

8. Expansion flexibility
9. Production flexibility

10. Program flexibility

11. Market flexibility

12. Response flexibility

13. Product mix flexibility

14. Size flexibility

15. Range flexibility

Based on the literature review and discussions with the industry experts and the academia, 15 factors were identified from (Raj et al., 2012; Sujono and Lashkari, 2007; Bayazit, 2005; Groover, 2007; Primrose, 1996; Kaighobadi and Venkatesh, 1994; Rao and Deshmukh, 1994). These factors are given below.

1. Ability to manufacture a Variety of products (Gupta and Goyal, 1989)

2. Capacity to handle new products (Fine and Freund, 1990)

3. Flexibility in Production (Grubbström and Olhager, 1997)

4. Flexible fixturing (Bi and Zhang, 2001)

5. Combination of operation (Kumar et al., 2006)

6. Automation (Jovane et al., 2003)

7. Use of automated material handling devices (Ganesharajah et al., 1998)

8. Increase machine utilization (Chen and Chung, 1991)
9. Use of the reconfigurable machine tool (Raj et al., 2008)

10. Manufacturing lead time \& set up-time reduction (Ferdows and De Meyer, 1990)

11. Speed of response (Daniels, 1993)

12. Reduced WIP inventories (Dimitrov, 1990)

13. Reduction in material flow (Mertins and Wieneke-Toutaoui, 1991)

14. Quality consciousness (Lee, 1992)

15. Reduction in scrap (Primrose, 1996)

Evaluation of these flexibilities is analysed by SAW and WPM. The criteria weights are calculated by using the Analytical hierarchy process (AHP). Purpose of evaluation of flexibility is to accord a proper attention of researchers and production managers to focus the flexibility in FMS.

The primary objectives of this paper are as follows:

- To identify flexibility and factors affecting the flexibility in FMS.

- To evaluate the flexibility by using SAW and WPM.

- To discuss managerial implication of this research.

In the remainder of this paper, an overview of the SAW and WPM Methodology is presented in section 2. In section 3, Use of SAW and WPM Methodology are discussed. The conclusion is followed in section 4 .

\section{Methodology}

The multiple attribute decision making (MADM) refers to an approach to problem solving that is employed to solve problems involving selected from among a finite number of alternatives. An 
MADM method is a procedure that specifies how attribute information is to be processed in order to arrive at a choice. The two decision making methods, which are Simple Additive Weighting (SAW) and Weighted Product Method (WPM), are integrated with Analytical hierarchy process (AHP) in order to get the best use of information available. The aim of using AHP is to give the weights of the attributes and these weights are used in SAW \& WPM method for ranking of flexibility in FMS. Furthermore, the method uses fuzzy logic to change the qualitative attributes into the quantitative attributes. Rao (2007) has consolidated the information on fuzzy MADM. Bellman and Zadeh (1970) were the first to relate fuzzy set theory to decision-making problems. Baas and Kwakernaak (1977) proposed a fuzzy MADM method that is widely regarded as the classic work of fuzzy MADM methods.

\subsection{Simple Additive Weighting (SAW) Method}

Churchman and Ackoff (1954) first utilized the SAW method to cope with a portfolio selection problem. The SAW method is probably the best known and widely used method for multiple attribute decision making MADM. Afshari et al. (2010) used this approach to the personnel selection problem; Chou et al. (2008) used for facility location selection with objective/subjective attributes; Zavadskas et al. (2010) has done Contractor selection for construction works with this approach. The main procedure to find the overall or a composite score of the alternative by SAW method is described below (Rao, 2007):

Step 1: The first step is to determine the objective, and to identify the pertinent evaluation attributes.

Step 2: This step represents a matrix based on all the information available on attributes. Each row of this matrix is allocated to one alternative, and each column to one attribute. In the case of a subjective attribute (i.e., objective value is not available), a ranked value judgment on a scale is adopted. Chen and Hwang (1992) proposed an approach to solve more than 10 alternatives, and they proposed first converts linguistic terms into fuzzy numbers and then the fuzzy numbers into crisp scores. An 11point scale is used in the paper is shown in Fig. 1 and crisp score is shown in Table 1.

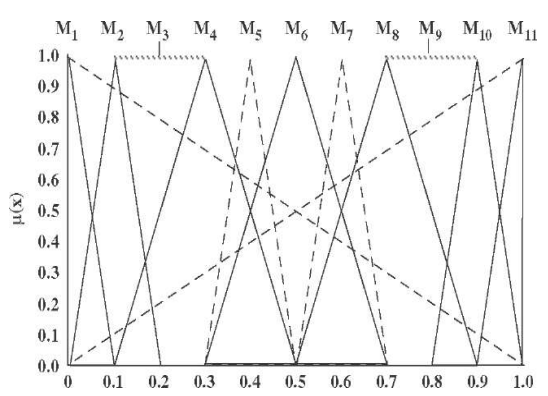

Table 1

Fig. 1. Linguistic term into their corresponding fuzzy numbers (11-point scale)

Conversion of linguistic terms into fuzzy scores (11-point scale)

\begin{tabular}{ccc}
\hline Linguistic term & Fuzzy no. & Crisp no. \\
\hline Exceptionally low & $\mathrm{M}_{1}$ & 0.045 \\
Extremely low & $\mathrm{M}_{2}$ & 0.135 \\
Very low & $\mathrm{M}_{3}$ & 0.255 \\
Low & $\mathrm{M}_{4}$ & 0.335 \\
Below average & $\mathrm{M}_{5}$ & 0.41 \\
Average & $\mathrm{M}_{6}$ & 0.5 \\
Above average & $\mathrm{M}_{7}$ & 0.59 \\
High & $\mathrm{M}_{8}$ & 0.665 \\
Very high & $\mathrm{M}_{9}$ & 0.745 \\
Extremely high & $\mathrm{M}_{10}$ & 0.865 \\
Exceptionally high & $\mathrm{M}_{11}$ & 0.955 \\
\hline
\end{tabular}


Step 3: The weights are calculated by using the Analytical hierarchy process (AHP). The steps are explained below:

$>$ Construct a pairwise comparison matrix using a scale of relative importance. The judgements are entered using the fundamental scale of the analytic hierarchy process (Saaty, 1994). An attribute compared with itself is always assigned the value 1, so the main diagonal entries of the pairwise comparison matrix are all 1 . The numbers 3, 5, 7, and 9 correspond to the verbal judgements 'moderate Importance ', ' strong importance ', ' very strong importance ' and ' absolute importance' (with 2, 4, 6, and 8 for compromise between these values).

$>$ Find the relative normalized weight $\left(\mathrm{w}_{\mathrm{j}}\right)$ of each attribute by (i) calculating the geometric mean of i-th row, and (ii) normalizing the geometric means of rows in the comparison matrix. This can be represented as follows

$$
\begin{aligned}
& G M_{J}=\left[\prod_{i=1}^{M} b_{i j}\right]^{\frac{1}{M}} \\
& W_{J}=G M_{j} / \sum_{j=0}^{M} G M_{j}
\end{aligned}
$$

The geometric mean method of AHP is commonly used to determine the relative normalized weights of the attributes, because of its simplicity, ease, determination of the maximum Eigenvalue, and reduction in inconsistency of judgments.

$>$ Calculate matrices A3 and A4 such that $\mathrm{A} 3=\mathrm{A} 1 * \mathrm{~A} 2$ and $\mathrm{A} 4=\mathrm{A} 3 / \mathrm{A} 2$.

$>$ Determine the maximum Eigenvalue $\lambda_{\max }$ that is the average of the matrix A4.Calculate the consistency index $\mathrm{CI}=\left(\lambda_{\max }-\mathrm{M}\right) /(\mathrm{M}-1)$. The smaller the value of $\mathrm{CI}$, the smaller is the difference from the consistency.

$>$ Obtain the random index (RI) for the number of attributes used in decision making.

$>$ Calculate the consistency ratio $\mathrm{CR}=\mathrm{CI} / \mathrm{RI}$. Usually, a CR of 0.1 or less is considered as acceptable, and it reflects an informed judgement attribute to the knowledge of the analyst regarding the problem under study.

Step 4: Construct a decision matrix $(\mathrm{m} \times \mathrm{m})$ that includes $\mathrm{m}$ alternatives and $\mathrm{m}$ attributes.

Compute the normalized decision matrix for beneficial attributes:

$m_{i j}=r_{i j} / r_{j}^{\max } \mathrm{i}=1, \ldots . . \mathrm{m}$ and $\mathrm{j}=1, \ldots . \mathrm{m}$

Compute the normalized decision matrix for non-beneficial properties:

$m_{i j}=r_{j}^{\min } / r_{i j} \mathrm{i}=1, \ldots . \mathrm{m}$ and $\mathrm{j}=1, \ldots . \mathrm{m}$

Step 5: Evaluate each alternative, $P_{i}$ by the following formula:

$P_{i}=\sum_{j=1}^{M} w_{j}\left(m_{i j}\right)_{\text {normal }}$

Where $\left(m_{i j}\right)_{\text {normal }}$ represents the normalized value of $m_{i j}$, and $P_{i}$ is the overall or composite score of the alternative $A_{i}$. The alternative with the highest value of is considered as the best option, as the best alternative.

\subsection{Weighted Product Method (WPM)}

This method is similar to SAW. The main difference is that, instead of the addition in the model, there is multiplication (Miller and Starr, 1969). The overall or composite performance score of an alternative is given by Eq. 6 . 
$P_{i}=\prod_{j=1}^{M}\left[\left(m_{i j}\right)_{n o r m a l}\right]^{w_{j}}$

The normalized values are computed as explained under the SAW method step 4. Each normalized value of an alternative with respect to an attribute, i.e., $\left(m_{i j}\right)_{n o r m a l}$ is raised to the power of the relative weight of the corresponding attribute. The alternative with the highest $P_{i}$ value is considered the best alternative.

\section{Evaluation of flexibility by SAW and WPM}

In this section, the evaluation of flexibility is carried out by SAW is described below.

Step 1: Objective is ranking of flexibility in FMS based on 15 attributes. All attributes the beneficial attributes, i.e. higher values are desired.

Step 2: Convert qualitative attribute to their corresponding fuzzy number and then converted to the crisp scores. The quantitative values of attributes are, given in fuzzy crisp values, given in Table 2 .

Step 3: Relative importance matrix (i.e. Weights) of different attributes with respect to the objective is taken with AHP methodology and find the weights as given below.

$\mathrm{w}_{1}=0.086, \mathrm{w}_{2}=0.085, \mathrm{w}_{3}=0.078, \mathrm{w}_{4}=0.136, \mathrm{w}_{5}=0.067, \mathrm{w}_{6}=0.121, \mathrm{w}_{7}=0.096, \mathrm{w}_{8}=0.035$,

$\mathrm{w}_{9}=0.095, \mathrm{w}_{10}=0.053, \mathrm{w}_{11}=0.019, \mathrm{w}_{12}=0.037, \mathrm{w}_{13}=0.030, \mathrm{w}_{14}=0.027, \mathrm{w}_{15}=0.035$.

The value of $\lambda_{\max }$ is 17.2112 and $\mathrm{CR}=0.0993$, which is less than allowed $\mathrm{CR}$ value of 0.1 . Thus, there is good consistency in the judgment made.

Step 4: Normalized decision matrix is made according to Eq. (3).

Step 5: Overall or composite score of the alternative i.e. $P_{i}$ is

$\mathrm{P}_{1}=0.799, \mathrm{P} 2=0.703, \mathrm{P} 3=0.763, \mathrm{P} 4=0.803, \mathrm{P} 5=0.712, \mathrm{P} 6=0.654, \mathrm{P} 7=0.605, \mathrm{P} 8=0.710, \mathrm{P} 9=0.789$, $\mathrm{P} 10=0.471$,

$\mathrm{P}_{11}=0.562, \mathrm{P} 12=0.774, \mathrm{P} 13=0.772, \mathrm{P} 14=0.742, \mathrm{P} 15=0.672$.

Ranking of flexibilities are 4-1-9-12-13-3-14-5-8-2-15-6-7-11-10.

By WPM:

Overall or composite score of the alternative i.e. $P_{i}$ is

$\mathrm{P}_{1}=14.76, \mathrm{P}_{2}=14.61, \mathrm{P}_{3}=14.71, \mathrm{P}_{4}=14.77, \mathrm{P}_{5}=14.64, \mathrm{P}_{6}=14.52, \mathrm{P}_{7}=14.47, \mathrm{P}_{8}=14.62, \mathrm{P}_{9}=14.75$, $\mathrm{P}_{10}=14.21, \mathrm{P}_{11}=14.36, \mathrm{P}_{12}=14.71, \mathrm{P}_{13}=14.73, \mathrm{P}_{14}=14.70, \mathrm{P}_{15}=14.58$.

Ranking of flexibilities are 4-1-9-13-3-12-14-5-8-2-15-6-7-11-10.

Table 2

Fuzzy or crisp value of Variables

\begin{tabular}{|c|c|c|c|c|c|c|c|c|c|c|c|c|c|c|c|}
\hline \multirow[b]{3}{*}{ Alternatives } & \multicolumn{15}{|c|}{ Attributes } \\
\hline & 1 & 2 & 3 & 4 & 5 & 6 & 7 & 8 & 9 & 10 & 11 & 12 & 13 & 14 & 15 \\
\hline & & & & & & & & & & & & & & & \\
\hline 1 & 0.865 & 0.665 & 0.665 & 0.5 & 0.59 & 0.5 & 0.41 & 0.59 & 0.665 & 0.665 & 0.59 & 0.335 & 0.255 & 0.5 & 0.41 \\
\hline 2 & 0.41 & 0.41 & 0.665 & 0.5 & 0.255 & 0.5 & 0.59 & 0.59 & 0.41 & 0.41 & 0.665 & 0.59 & 0.5 & 0.41 & 0.5 \\
\hline 3 & 0.665 & 0.5 & 0.59 & 0.59 & 0.5 & 0.5 & 0.41 & 0.59 & 0.5 & 0.5 & 0.59 & 0.5 & 0.5 & 0.41 & 0.5 \\
\hline 4 & 0.745 & 0.865 & 0.665 & 0.59 & 0.41 & 0.5 & 0.41 & 0.59 & 0.59 & 0.5 & 0.665 & 0.41 & 0.41 & 0.5 & 0.41 \\
\hline 5 & 0.41 & 0.41 & 0.41 & 0.5 & 0.5 & 0.59 & 0.59 & 0.5 & 0.5 & 0.665 & 0.5 & 0.41 & 0.41 & 0.41 & 0.41 \\
\hline 6 & 0.255 & 0.255 & 0.41 & 0.41 & 0.5 & 0.59 & 0.745 & 0.41 & 0.41 & 0.59 & 0.59 & 0.5 & 0.41 & 0.335 & 0.255 \\
\hline 7 & 0.335 & 0.255 & 0.41 & 0.5 & 0.41 & 0.5 & 0.41 & 0.41 & 0.59 & 0.5 & 0.41 & 0.335 & 0.335 & 0.255 & 0.255 \\
\hline 8 & 0.41 & 0.335 & 0.665 & 0.5 & 0.5 & 0.41 & 0.5 & 0.665 & 0.745 & 0.745 & 0.5 & 0.335 & 0.255 & 0.41 & 0.255 \\
\hline 9 & 0.665 & 0.59 & 0.59 & 0.59 & 0.5 & 0.665 & 0.59 & 0.665 & 0.865 & 0.41 & 0.41 & 0.255 & 0.335 & 0.5 & 0.135 \\
\hline 10 & 0.255 & 0.255 & 0.335 & 0.255 & 0.135 & 0.5 & 0.59 & 0.335 & 0.41 & 0.335 & 0.59 & 0.255 & 0.255 & 0.135 & 0.135 \\
\hline 11 & 0.5 & 0.59 & 0.5 & 0.335 & 0.255 & 0.665 & 0.135 & 0.255 & 0.59 & 0.255 & 0.5 & 0.255 & 0.135 & 0.5 & 0.135 \\
\hline 12 & 0.5 & 0.59 & 0.665 & 0.59 & 0.335 & 0.745 & 0.59 & 0.41 & 0.5 & 0.335 & 0.5 & 0.255 & 0.41 & 0.665 & 0.5 \\
\hline 13 & 0.59 & 0.5 & 0.665 & 0.5 & 0.5 & 0.59 & 0.5 & 0.5 & 0.5 & 0.59 & 0.5 & 0.59 & 0.41 & 0.5 & 0.5 \\
\hline 14 & 0.665 & 0.59 & 0.5 & 0.5 & 0.5 & 0.5 & 0.59 & 0.5 & 0.59 & 0.665 & 0.5 & 0.41 & 0.335 & 0.335 & 0.255 \\
\hline 15 & 0.5 & 0.5 & 0.59 & 0.5 & 0.41 & 0.5 & 0.59 & 0.41 & 0.5 & 0.5 & 0.59 & 0.335 & 0.255 & 0.255 & 0.135 \\
\hline
\end{tabular}




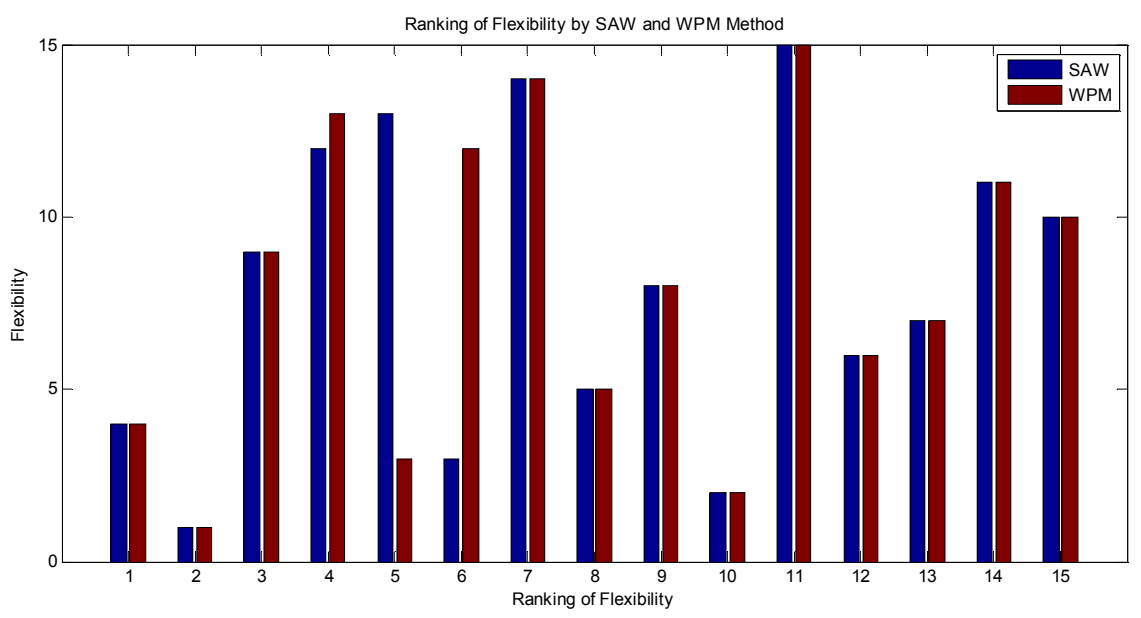

Fig. 2. Ranking of Flexibility by SAW and WPM Method

\section{Discussion and Conclusion}

The major aim of this paper is to identify the flexibilities and factors that significantly affect the flexibility of FMS in any industry so that management may effectively deal with these factors. In this paper, we perform multi attribute decision making (MADM) like SAW and WPM for evaluation of flexibility in FMS by fifteen attributes using qualitative data. A three step approach is used for the evaluation of flexibility. In the first step, Convert qualitative attribute to their corresponding fuzzy number and then converted to the crisp scores. In the second step, Weights of different attributes with respect to the objective is found by AHP methodology. In the third step, The MADM techniques like SAW and WPM is used in our study and concluded that Product flexibility is the most important flexibility in the FMS and Program Flexibility has the least impact in these 15 flexibilities. Ranking of Flexibility by SAW and WPM Method is shown in fig. 2. So, the practicing manager can focus on this flexibility in FMS.

\section{Acknowledgement}

The authors acknowledge the anonymous referee of this paper for his or her valuable suggestions, which have helped to improve the quality of this paper.

\section{References}

Afshari, A., Mojahed, M., \& Yusuff, R. M. (2010). Simple additive weighting approach to personnel selection problem. International Journal of Innovation, Management and Technology, 1(5), 20100248.

Azzone, G., \& Bertele, U. (1989). Measuring the economic effectiveness of flexible automation: a new approach. International Journal of Production Research, 27 (5), 735-746.

Baas, S. M., \& Kwakernaak, H. (1977). Rating and ranking of multiple-aspect alternatives using fuzzy sets. Automatica, 13 (1), 47-58. doi: http://dx.doi.org/10.1016/0005-1098(77)90008-5

Bayazit, O. (2005). Use of AHP in decision-making for flexible manufacturing systems. Journal of Manufacturing Technology Management, 16 (7), 808-819.

Bellman, R. E., \& Zadeh, L. A. (1970). Decision-making in a fuzzy environment. Management Science, 17 (4), B-141-B-164. 
Bi, Z., \& Zhang, W. (2001). Flexible fixture design and automation: review, issues and future directions. International Journal of Production Research, 39 (13), 2867-2894.

Browne, J., Dubois, D., Rathmill, K., Sethi, S. P., \& Stecke, K. E. (1984). Classification of flexible manufacturing systems. The FMS magazine, 2 (2), 114-117.

Buzacott, J. A. (1982). The fundamental principles of flexibility in manufacturing systems. Paper presented at the Proceedings of the 1st International Conference on Flexible Manufacturing Systems Brighton, UK, 13-22.

Chan, F. T., Kazerooni, A., \& Abhary, K. (1997). A fuzzy approach to operation selection. Engineering Applications of Artificial Intelligence, 10 (4), 345-356.

Chen, I. J., \& Chung, C.-h. (1991). Effects of loading and routeing decisions on performance of flexible manufacturing systems. The International Journal of Production Research, 29 (11), 22092225.

Chen, S., Hwang, C., \& Hwang, F. (1992). Fuzzy multiple attribute decision making: Methods and applications. Springer-Verlag, Berlin.

Chou, S.Y., Chang, Y.H., \& Shen, C.Y. (2008). A fuzzy simple additive weighting system under group decision-making for facility location selection with objective/subjective attributes. European Journal of Operational Research, 189 (1), 132-145.

Churchman, C. W., \& Ackoff, R. L. (1954). An approximate measure of value. Operations Research, $2(2), 172-187$.

Daniels, S. (1993). Flexible manufacturing systems. Work Study, 42 (5), 23-25.

Dimitrov, P. (1990). The impact of flexible manufacturing systems (FMS) on inventories. Engineering Costs and Production Economics, 19 (1), 165-174.

Ferdows, K., \& De Meyer, A. (1990). Lasting improvements in manufacturing performance: in search of a new theory. Journal of Operations management, 9 (2), 168-184.

Fine, C. H., \& Freund, R. M. (1990). Optimal investment in product-flexible manufacturing capacity. Management Science, 36 (4), 449-466.

Ganesharajah, T., Hall, N. G., \& Sriskandarajah, C. (1998). Design and operational issues in AGVserved manufacturing systems. Annals of Operations Research, 76, 109-154.

Groover, M. P. (2007). Automation, production systems, and computer-integrated manufacturing. New Delhi : Prentice-Hall.

Grubbström, R. W., \& Olhager, J. (1997). Productivity and flexibility: fundamental relations between two major properties and performance measures of the production system. International Journal of Production Economics, 52 (1), 73-82.

Gupta, Y. P., \& Goyal, S. (1989). Flexibility of manufacturing systems: concepts and measurements. European Journal of Operational Research, 43(2), 119-135.

Jovane, F., Koren, Y., \& Boer, C. (2003). Present and future of flexible automation: towards new paradigms. CIRP Annals-Manufacturing Technology, 52 (2), 543-560.

Kaighobadi, M., \& Venkatesh, K. (1994). Flexible manufacturing systems: an overview. International Journal of Operations \& Production Management, 14 (4), 26-49.

Kumar, A., Tiwari, M., Shankar, R., \& Baveja, A. (2006). Solving machine-loading problem of a flexible manufacturing system with constraint-based genetic algorithm. European Journal of Operational Research, 175 (2), 1043-1069.

Lee, C. Y. (1992). The adoption of Japanese manufacturing management techniques in Korean manufacturing industry. International Journal of Operations \& Production Management, 12(1), 66-81.

Mertins, K., \& Wieneke-Toutaoui, B. (1991). State of the art in flexible manufacturing system design. Production planning \& Control, 2 (2), 155-159.

Miller, D., \& Starr, M. (1969). Executive decisions and operations research. NJ : Englewood Cliffs,Prentice-Hall.

Park, C. S., \& Son, Y. K. (1988). An economic evaluation model for advanced manufacturing systems. The Engineering Economist, 34 (1), 1-26. 
Primrose, P. L. (1996). Do companies need to measure their production flexibility? International Journal of Operations \& Production Management, 16 (6), 4-11.

Raj, T., Attri, R., \& Jain, V. (2012). Modelling the factors affecting flexibility in FMS. International Journal of Industrial and Systems Engineering, 11 (4), 350-374.

Raj, T., Shankar, R., \& Suhaib, M. (2008). An ISM approach for modelling the enablers of flexible manufacturing system: the case for India. International Journal of Production Research, 46 (24), 6883-6912.

Rao, K. S., \& Deshmukh, S. (1994). Strategic framework for implementing flexible manufacturing systems in India. International Journal of Operations \& Production Management, 14 (4), 50-63.

Rao, R. V. (2007). Decision making in the manufacturing environment: using graph theory and fuzzy multiple attribute decision making methods. London: Springer-Verlag.

Saaty, T. L. (1994). Fundamentals of decision making and priority theory with the analytic hierarchy process (Vol. 4922). Pittsburg : RWS Publications.

Sethi, A. K., \& Sethi, S. P. (1990). Flexibility in manufacturing: a survey. International journal of flexible manufacturing systems, 2 (4), 289-328.

Son, Y. K., \& Park, C. S. (1990). Quantifying opportunity costs associated with adding manufacturing flexibility. International journal of production research, 28 (6), 1183-1194. doi: $10.1080 / 00207549008942784$

Stockton, D., \& Bateman, N. (1995). Measuring the production range flexibility of a FMS. Integrated Manufacturing Systems, 6 (2), 27-34.

Sujono, S., \& Lashkari, R. (2007). A multi-objective model of operation allocation and material handling system selection in FMS design. International Journal of Production Economics, 105 (1), 116-133.

Zavadskas, E. K., Vilutiene, T., Turskis, Z., \& Tamosaitiene, J. (2010). Contractor selection for construction works by applying SAW-G and TOPSIS grey techniques. Journal of Business Economics and Management, 11 (1), 34-55. 